\title{
Storage of vaccines in the community: weak link in the cold chain?
}

\author{
Yogini Thakker, Sheila Woods
}

\begin{abstract}
Objective-To assess quality of storage of vaccines in the community.

Design-Questionnaire survey of general practices and child health clinics, and monitoring of storage temperatures of selected refrigerators.

Setting - Central Manchester and Bradford health districts.

Subjects -45 general practices and five child health clinics, of which $40(80 \%)$ responded. Eight practices were selected for refrigeration monitoring.

Main outcome measures-Adherence to Department of Health guidelines for vaccine storage, temperature range to which vaccines were exposed over two weeks.

Results-Of the 40 respondents, only 16 were aware of the appropriate storage conditions for the vaccines; eight had minimum and maximum thermometers but only one of these was monitored daily. In six of the eight practices selected for monitoring of refrigeration temperatures the vaccines were exposed to either subzero temperatures (three fridges) or temperatures up to $16^{\circ} \mathrm{C}$ (three). Two of these were specialised drug storage refrigerators with an incorporated thermostat and external temperature gauges.

Conclusion-Vaccines were exposed to temperatures that may reduce their potency. Safe storage of vaccines in the clinics cannot be ensured without adhering to the recommended guidelines. Provision of adequate equipment and training for staff in maintaining the "cold chain" and the use and care of equipment are important components of a successful immunisation programme.
\end{abstract}

\section{Introduction}

Much money, time and effort has been put into the current national immunisation programme to ensure its success. One of the factors affecting success is the storage of vaccines. Vaccines must be stored at the temperatures recommended by manufacturers in order to maintain their potency. ${ }^{1-4}$

Guidelines exist at both national ${ }^{5}$ and local ${ }^{6}$ levels to minimise exposure of vaccines to adverse temperatures during storage. The national guidelines recommend that, firstly, vaccines received are immediately placed under the required storage conditions (polio $0-4^{\circ} \mathrm{C}$, other vaccines $2-8^{\circ} \mathrm{C}$ ) and that a nominated, trained person should be responsible for vaccine storage. This person should be able to work to a written procedure developed to meet local needs. Secondly, the temperature of the refrigerator should be monitored with a minimum and maximum thermometer irrespective of whether the refrigerator incorporates a thermometer dial and the maximum and minimum temperatures should be recorded regularly. Written procedures should indicate the action to be taken if the temperature goes outside the specified range. Thirdly, if the refrigerator has no automatic defrosting facility it ڤ should be defrosted regularly. During defrosting the $\vec{\circ}$ vaccines should be stored in an alternative refrigerator or cool box. Fourthly, reconstituted vaccine must be used within the manufacturers' recommended period. Partially used multidose phials must be destroyed at the end of the session.

In Third World countries where ambient temperatures are high the monitoring of the "cold chain" from production to delivery of vaccines to patients is given high priority. A recent study from a temperate country showed considerable weaknesses in the cold chain of during transportation from the manufacturer to the child health clinics. ${ }^{78}$ Similar weaknesses may exist in $N$ the British cold chain system. Additional exposure to $\vec{z}$ adverse temperatures within the clinics could reduce the potency of the vaccines. Our study was undertaken to assess the quality of storage of vaccines in general practices and community child health clinics in two health districts.

\section{Subjects and methods}

We obtained a list of general practices and community child health clinics participating in childhood immunisation from the immunisation centre for Central Manchester Health Authority. There were a total of 30 practices and 10 child health clinics. We listed the centres in alphabetical order and selected every alternate one for inclusion in the study (15 practices and five child health clinics)

We also obtained a list of general practitioners practising in the Bradford area (total 255). General practitioners were listed in alphabetical order and every eighth one was selected; if a general practitioner was selected from a practice already represented the next practitioner on the list was substituted. Thus 30 practices $(27 \%$ of practices in Bradford area) were ô included in the study.

A questionnaire on vaccine storage was sent to the selected centres together with a letter emphasising the $N$ anonymity and confidentiality of the respondents' N answers and a self addressed envelope for returning the 0 questionnaire. Non-respondents were not followed up as they were unidentifiable.

Eight centres were selected for monitoring of temperatures in the refrigerators. The four centres closest $\tau$ to our workplaces were chosen as this allowed close $\overline{0}$ contact with the person in charge of vaccine storage. We gave verbal and written instructions on using $\underset{\mathbb{D}}{\mathbb{8}}$ maximum and minimum thermometers, which we provided. The refrigerators consisted of eight domestic refrigerators and two wall mounted drug storage cabinets with incorporated thermostats and external temperature gauges. The thermometers were placed in $\frac{0}{7}$ the middle of the storage area. Although vertical positioning was recommended by the manufacturers the thermometers were placed horizontally because of the limited space. Previous comparisons between 


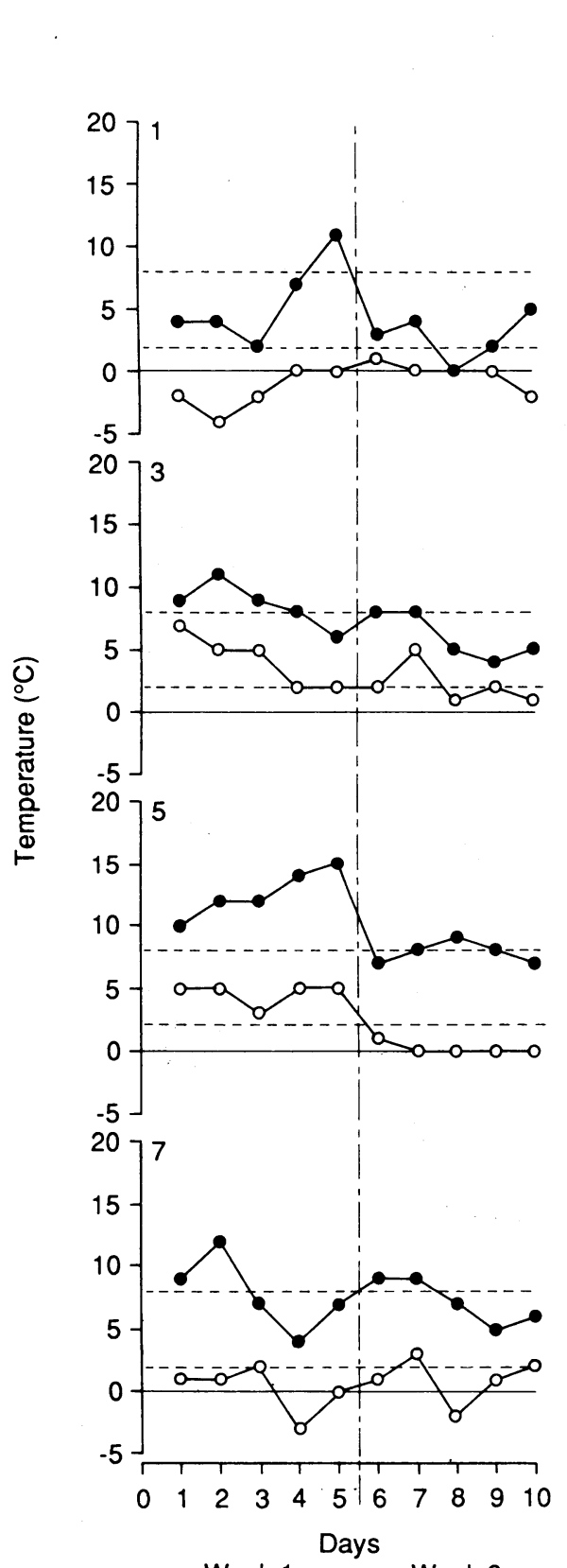

Week 1
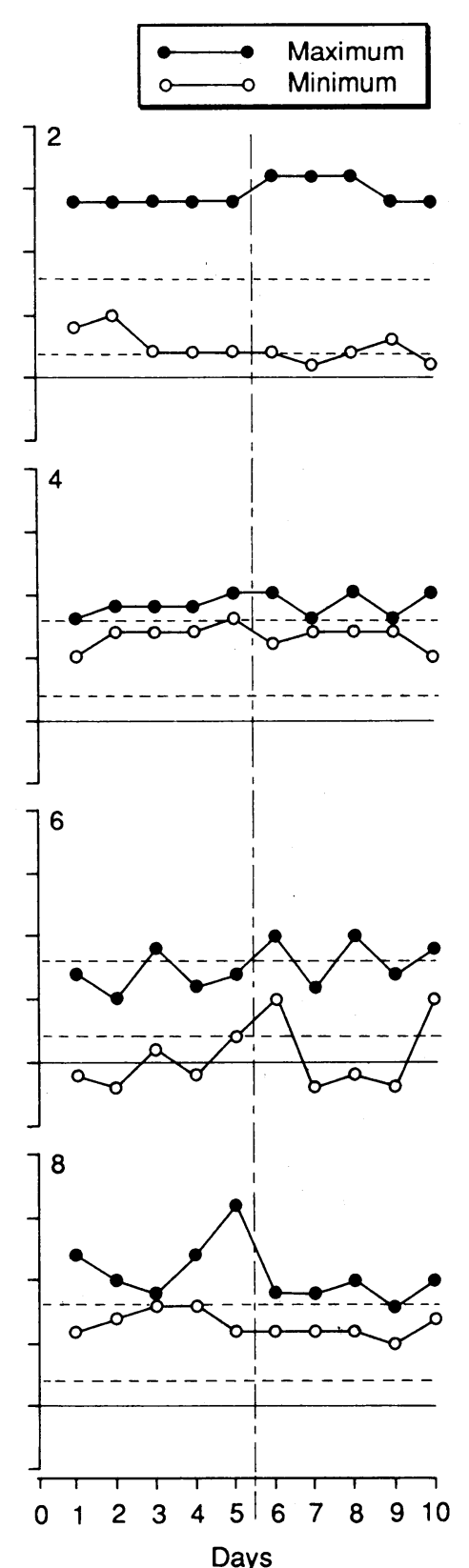

Week 1

(figure). This variation occurred in both domestic and specialised storage refrigerators. In two of the practices difficulties were encountered with reading the maximum and minimum value of the thermometer and a falsely wide range of temperatures was recorded (for example, $-12^{\circ} \mathrm{C}$ to $12^{\circ} \mathrm{C}$ ). In six of the remaining eight refrigerators the vaccines were exposed to either subzero temperatures or temperatures up to $16^{\circ} \mathrm{C}$. One of the domestic refrigerators was used for storing other items, including food and drink. Neither of the two specialised vaccine storage refrigerators (numbers 7 and 8 ) were able to maintain the temperatures within the preset zone, between $2^{\circ} \mathrm{C}$ and $6^{\circ} \mathrm{C}$.

\section{Discussion}

Vaccines vary in their sensitivity to adverse storage conditions and manufacturers offer guidelines for storage temperatures to ensure potency. Information is available on stability of vaccines at the temperature ranges of subzero, $0-8^{\circ} \mathrm{C}, 22-25^{\circ} \mathrm{C}, 35-37^{\circ} \mathrm{C}$, and over $37^{\circ} \mathrm{C} .{ }^{+}$At temperatures of $22-25^{\circ} \mathrm{C}$ the toxoids, diphtheria, and tetanus are stable for months; pertussis vaccine is stable for a maximum of two weeks; oral poliomyelitis vaccine loses $50 \%$ of its potency after 20 days; freeze dried measles vaccine retains satisfactory potency for one month; and hepatitis $B$ vaccine is stable for 30 days. If freezing occurs there is a significant loss of potency with adsorbed diphtheria, tetanus, and pertussis vaccine ${ }^{9}$ and hepatitis B vaccine. ${ }^{10}$

The effect of adverse temperatures on vaccines is cumulative. Vaccines stored in the community will not be able to withstand temperatures outside the recommended range if their potency has already been compromised by previous breaks in the cold chain such as may occur during transportation.

Our study shows poor adherence to the national guidelines for vaccine storage and exposure of vaccines to a wide range of temperatures. With the high response rate and little variation in the responses between the two areas, we believe our results are representative of the quality of storage of vaccines in the areas studied. A questionnaire survey distributed among practice nurses in Hampshire and Dorset also showed lack of awareness of the recommended storage conditions for vaccines. ${ }^{11}$

Storage conditions which preserve the potency of vaccines may be achieved simply and cheaply. We suggest that, firstly, awareness of the loss of potency of incorrectly stored vaccines is increased. Secondly, there should be adherence to the national guidelines on

horizontally and vertically placed thermometers in the same compartment of a bigger refrigerator had shown differences no greater than $0.5^{\circ} \mathrm{C}$. The thermometers were read daily (Monday to Friday) for two weeks.

\section{Results}

We received 40 completed questionnaires (25 from Bradford, 15 from Manchester), giving an overall response rate of $80 \%$. The table shows the results of the analysis of the responses to the questionnaires. Of the 40 respondents, only 16 were aware of the appropriate storage conditions for the vaccines. Eight centres had a maximum and minimum thermometer but only one monitored it daily. Four centres did not have a designated person responsible for the storage of vaccines. Among the remainder, in 26 the designated person was a nurse, and in nine the person was not medical (practice managers, receptionists, and clinic attendants).

In those centres in which we provided a maximum and minimum thermometer wide variations outside the recommended temperature ranges were recorded, with temperatures as high as $16^{\circ} \mathrm{C}$ and as low as $-4^{\circ} \mathrm{C}$

Storage of vaccines in general practices and clinics performing childhood immunisations

\begin{tabular}{|c|c|c|c|}
\hline & $\begin{array}{l}\text { Bradford } \\
(\mathbf{n}=25)\end{array}$ & $\begin{array}{c}\text { Central } \\
\text { Manchester } \\
(\mathbf{n}=15)\end{array}$ & $\begin{array}{c}\text { Total } \\
(\mathbf{n}=40)\end{array}$ \\
\hline \multicolumn{4}{|l|}{ Designated person looking after fridge: } \\
\hline Practice nurse & 17 & 5 & 22 \\
\hline Practice manager & 5 & 1 & 6 \\
\hline Health visitor & & 3 & 3 \\
\hline Doctor & & 1 & 1 \\
\hline $\begin{array}{l}\text { Other (clinic attendant, school nurse, } \\
\text { receptionist) }\end{array}$ & 2 & 2 & 4 \\
\hline None or not specified & 1 & 3 & 4 \\
\hline \multicolumn{4}{|l|}{ Thermometer in the fridge: } \\
\hline Incorporated dial & 4 & 6 & 10 \\
\hline Maximum and minimum & 7 & 1 & 8 \\
\hline Strip & 1 & & 1 \\
\hline None or not specified & 13 & 8 & 21 \\
\hline \multicolumn{4}{|l|}{ Temperature monitored: } \\
\hline Daily & 1 & & 1 \\
\hline Twice/week to once/month & 8 & 3 & 11 \\
\hline Not monitored & 16 & 12 & 28 \\
\hline \multicolumn{4}{|l|}{ Ideal storage temperature $\left({ }^{\top} \mathrm{C}\right)$ : } \\
\hline $2-8$ & 11 & 5 & 16 \\
\hline $0-4$ & 2 & 4 & 6 \\
\hline Other & 5 & 2 & 7 \\
\hline Not known & 7 & 4 & 11 \\
\hline
\end{tabular}


vaccine storage. Particular attention should be given to training of people responsible for vaccine storage, in the use and care of equipment such as maximum and minimum thermometers and thermostat controls. The maximum and minimum storage temperatures should be recorded daily irrespective of the type of refrigerator, and the thermostat should be adjusted when temperatures are outside the recommended range. Thirdly, use of the refrigerator for storing other items should be minimised to avoid frequent opening of the door, and, fourthly, local guidelines should address the safe storage of vaccines during transportation.

The cold chain for vaccines is a vulnerable point for the immunisation programme. Ensuring that each phial of vaccine is maintained under appropriate conditions until used will safeguard the programme's success.

We thank Dr G Roland, Central Manchester Health Authority, for her advice and support; Dr I Ferguson,
Haworth Surgeries; and all those who participated in the survey.

1 Longland P, Rowbottom P. Room temperature stability of medicines recommended per cold storage. Pharmaceutical fournal 1989;4:584-94.

2 Sokhey J, Gupta CJ, Sharma B, Singh H. Stability of oral polio vaccine at different temperature. Vaccine 1988:6:12-3.

3 Manufacturers recommendations regarding stability of vaccines at room temperatures. London: Smith, Kline and French, 1990

4 World Health Organisation. Expanded programme on immunisation-stability of vaccines. Geneva: WHO, 1989.

Department of Health Joint Committee on Vaccination and Immunisation. Immunisation against infectious disease. London: HMSO, 1990.

Immunisation against infectious disease. London. HMSO, 1990. Manchester: CMHA, 1990:6-7.

7 Lugosi L, Battersby A. Transport and storage of vaccines in Hungary. Bull World Health Organ 1990;68:431-3.

8 Expanded programme on immunisation-cold chain evaluation. Wkly Epidemiol Rec 1990;65:181-4.

9 Expanded programme on immunisation: the effects of freezing on the appearance, potency, and toxicity of adsorbed and unadsorbed DPT vaccines. Wkly Epidemiol $R e c$ 1980;55:385-9, 396-8.

10 McLean AA, Shaw R. Hepatitis B virus vaccine. Ann.Intern Med 1982;97:451. 11 Hunter S. Storage of vaccines in general practice. BMJ 1989;299:661-2.

(Accepted 16 fanuary 1991)

\title{
Asthma care in Darley Dale: general practitioner audit
}

\author{
Cedrick R Martys
}

\begin{abstract}
Objective-To complete a first audit cycle of asthma care in Darley Dale after starting an asthma clinic.
\end{abstract}

Design-Pre-clinic (1989) and post-clinic (1990) analysis of medical records of patients with asthma.

Setting-A group practice in Derbyshire.

Patients-161 pre-clinic, 238 post-clinic patients with asthma.

Main outcome measures-Term "asthma" in the patient's computerised problem list, recording of peak expiratory flow rate, smoking history, clinical review, medication, and hospital admissions for asthma.

Results-There were significant improvements post-clinic with respect to the term "asthma" in the computer file (1989, 93/161 (58\%); 1990, 233/238 (98\%) (difference $0.40 ; 95 \%$ confidence interval 0.32 to 0.48$)$ ); at least one peak flow measurement (1989, $24 / 161(15 \%) ; 1990,143 / 238(60 \%)(0.45 ; 0.37$ to $0.53)$ ); three or more peak flow measurements $(1989$, $15 / 161(9 \%) ; 1990,40 / 238(17 \%)(0.08 ; 0.02$ to 0.14$))$; and smoking history $(1989,24 / 161(15 \%) ; 1990$, $133 / 238(56 \%)(0.41 ; 0.33$ to 0.49$))$. There were no significant differences post-clinic with respect to asthma reviewed at least once $(1989,61 / 161(38 \%)$; $1990,74 / 238(31 \%)(0.07 ;-0.03$ to 0.17$))$; recording long term medication; treating acute asthma; or ratio of average to best peak flow rate of 38 .patients who had one or more measurements $(1989,31 / 38(82 \%)$; $1990,34 / 38(89 \%)(0.08 ;-0.08$ to 0.24$))$.

Conclusions - Setting up an asthma clinic resulted in better recording of data relevant to patients with asthma. However, objective improvement in patients' asthma could not be detected. Renewed emphasis on prophylactic measures may result in measurable improvement in these patients' asthma in the future.

Centre, Darley Dale,

Matlock, Derbyshire DE4 2SA

Cedrick R Martys, MD, general practitioner

Correspondence to: Cedrick R Martys.

BMf 1992;304:758-60

\section{Introduction}

Asthma is a common illness in the United Kingdom; $6 \%$ of the population have asthma, and it is responsible for 2000 deaths a year. ${ }^{1}$ It is estimated that more than $10 \%$ of children have asthma and that the prevalence, severity, and mortality have increased in recent years in both adults and children. ${ }^{23}$ Suboptimal care in general practice has contributed to this state of affairs. ${ }^{45}$ Recently guidelines on the management of asthmatic patients have been published. ${ }^{267}$ These provide detailed recommendations for prophylaxis and management of acute and chronic asthma, but it is too early to evaluate their impact on the care of asthmatic patients in the community.

For many years we have held special clinics in the Darley Dale practice for patients with hypertension and diabetes, and, although these have not been the subject of any formal audit procedures, we believed that better care was provided for patients attending these clinics than was the case previously. In 1989 we had felt for some time that we were not providing optimal care for our asthmatic patients, and when my trainee at the time expressed an interest in the management of asthma we worked to produce a practice protocol, which led to the establishment of an asthma clinic.

The aim of this audit was to ascertain whether better care has been provided for our asthmatic patients as a result of setting up the asthma clinic.

\section{Subjects and methods}

This training partnership of four principals is based in semirural west Derbyshire. The practice maintains three fully equipped surgeries, but the audit of asthma care was restricted to patients attending our main medical centre in Darley Dale. The pre-clinic audit and setting up of the asthma clinic were undertaken by Beverley Howson as a trainee project submitted for the local Syntex essay competition. The post-clinic audit was undertaken by me.

\section{PRE-CLINIC AUDIT}

Patients with asthma were identified by searching the practice computerised medical records for the term "asthma" in the computer problem list and searching the medication record for any record of long term treatment that is commonly prescribed to patients with asthma-for example, salbutamol or beclomethasone dipropionate inhalers. Patients so identified were sent a letter (addressed to the parents of subjects under 18) inviting them to attend the surgery for a consultation 